\title{
DETECTION OF LISTERIA MONOCYTOGENES IN RAW MILK AND READY TO EAT DAIRY PRODUCTS WITH EVALUATING THE ANTIMICROBIAL EFFECT OF COLD- PRESSED NIGELLA SATIVA OIL
}

\author{
HANAA M. FADEL ${ }^{1}$ and JEHAN ISMAIL ${ }^{2}$ \\ ${ }^{1}$ Department of Animal Hygiene and Zoonoses, Faculty of Veterinary Medicine, Suez Canal University, Ismailia, Egypt \\ ${ }^{2}$ Department of Food Hygiene, Milk Hygiene and Control, Faculty of Veterinary Medicine, Suez Canal University, Ismailia, \\ Egypt
}

Received: 24 January 2016; Accepted: 17 February 2016

\begin{abstract}
The objectives of this study were to evaluate the public health significance of Listeria monocytogenes in milk and some dairy products and to estimate the antimicrobial effect of Nigella sativa oil on artificially contaminated soft Damietta cheese. The highest prevalence rate of L. monocytogenes was detected in goat milk $(26.7 \%)$ followed by buffalo milk \& yoghurt (13.3\% each) then kareish cheese $(10 \%)$ and finally sheep milk samples $(6.7 \%)$. CHROMagar ListeriaTM ${ }^{\mathrm{TM}}$ medium performed better than Oxford agar medium in detection of $L$. monocytogenes. Out of the 90 samples tested, 21/90 (23.3\%) and 13/90 (14.4\%) were presumptively positive for Listeria spp. on Oxford agar and CHROMagar Listeria ${ }^{\mathrm{TM}}$ media, respectively. Further biochemical identification of the suspect colonies on Oxford agar and the chromogenic medium revealed that 5/21 (23.8\%) and 12/13 $(92.3 \%)$ of the isolated organisms, respectively were confirmed as L. monocytogenes. by applying PCR technique for detection of listeriolysin (hly A) gene, $3 / 90(3.3 \%)$ of the total examined samples and 3/12 (25\%) of biochemically confirmed isolates were positive (gave specific $750 \mathrm{bp}$ band). A trial was made to control $L$. monocytogenes contamination in Damietta cheese by using cold-pressed Nigella sativa oil. The results revealed a progressive highly significant reduction in the logarithmic count of L. monocytogenes $(\mathrm{P} \leq 0.01)$ in the sample treated with this oil.
\end{abstract}

Key words: Listeria monocytogenes, Raw Milk, Dairy Products, N. Sativa oil

\section{INTRODUCTION}

Food-borne diseases can cause serious and sometimes lethal infection in humans. Listeriosis is one of the most important food-borne diseases. It is mainly caused by Listeria monocytogenes. It is Grampositive bacterium capable of multiplying at a wide range of $\mathrm{pH}$, osmolarity and temperature (Sleator et al., 2003). Several food types have been implicated in transmission of this organism including milk and dairy products. Post-pasteurization contamination is the major source of Listeria spp. in dairy products (Conly and Johston, 2008).

Pregnant women, immune-compromised, children and elderly persons are considered to be at high risk of contracting the disease. The disease is manifested

Corresponding author: Dr. JEHAN ISMAIL

E-mail address: Jehanismail14@yahoo.com

Present address: Department of Food Hygiene, Milk Hygiene and Control, Faculty of Veterinary Medicine, Suez Canal University, Ismailia, Egypt by septicemia, meningitis, spontaneous abortion or stillbirths. However, it has also been associated with gastroenteritis and fever with a high fatality rate 25 $30 \%$ (CDC, 2013). On farm, the organism can grow in muddy and dusty soil. Moreover, it can be excreted in feces and milk of both symptomatic and asymptomatic animals (ADASC, 2000). An important character that makes L. monocytogenes of public health significance is its ability to form biofilms and survive on materials commonly used in food processing equipments (Silva et al., 2014).

According to (EC 2073/2005) (European Commission, 2005), the allowable limit of $L$. monocytogenes in food must not exceed $100 \mathrm{cfu} / \mathrm{g}$ throughout the shelf life of the product. Cheeses are considered to be possible vehicles of contamination for L. monocytogenes (CDC, 2015). They are exposed to several conditions that are favorable to the development of microorganisms. These conditions include unhygienic manipulation during processing, storage and distribution of the cheese and the mixture of different ingredients included in the cheese. $L$. monocytogenes is capable to grow at refrigerating 
temperatures, so the adoptions of natural antimicrobial strategies to overcome the tolerance of L. monocytogenes at low temperatures are essential (Mahgoub et al., 2013).

Therefore, the aim of this study was based to determine the prevalence rate of L. monocytogenes in raw buffalo milk, sheep milk, goat milk, yogurt and kareish cheese in Ismailia city and to control this pathogen by using natural antibacterial preservative.

\section{MATERIALS AND METHODS}

\section{Sample collection and preparation:}

- A total of 90 samples including raw buffalo milk, sheep milk, goat milk, plain yogurt (15 each) and kareish cheese (30) were collected from retail outlets, street vendors and free reared sheep and goat flocks in Ismailia City, Egypt. All samples were transferred in an ice-box at $4{ }^{\circ} \mathrm{C}$ to the lab to investigate the presence of Listeria monocytogenes.

- Preparation of samples for microbiological examination was done according to APHA, 2004.

\section{Isolation and identification of Listeria} monocytogenes (Roberts et al., 1995):

Twenty five grams (or $\mathrm{ml}$ ) of each sample were weighed into sterile stomacher bags and diluted with $225 \mathrm{ml}$ of Listeria pre-enrichment broth (Oxoid CM 895 ) then homogenized in a stomacher (Lab blender 400, Seward Medical, London, UK). All samples were first enriched using cold enrichment method (Jami et al., 2010). The inoculated broth was incubated at $4{ }^{\circ} \mathrm{C}$ for 7-10 days. Two loopful of the enrichment broth were sequentially plated on surface of Listeria oxford agar (Lab122, Lab M Limited, UK) supplemented with X123 and CHROMagar Listeria TM (LM 851 (B), Paris, France) supplemented with LM851(S). All plates were incubated at $37^{\circ} \mathrm{C}$ for 48 h. Five presumptive colonies from forementioned media were purified on tryptone soy agar (Oxoid, CM 131) with $0.6 \%$ yeast extract (Oxoid, Basingstoke, $\mathrm{UK}$ ), incubated at $37^{\circ} \mathrm{C}$ for $24-48 \mathrm{~h}$ for further morphological and biochemical identification (CFSAN, 2001). Moreover, two other selective media were used for further confirmation of the suspect colonies; Agosti \& Ottavianni Listeria agar [ALOA] (Oxoid CM1080), and PALCAM agar (Oxoid CM 877) supplemented with PALCAM selective supplement (SR150).

\section{Confirmation of the isolates by PCR DNA extraction and PCR amplification:}

DNA extraction was performed according to the manufacturer's guidelines using Bacterial DNA Extraction Kit (Spin-column) (BioTeke Corporation). Amplification reactions were carried out with $5 \mu 1$ of the eluted solution, $5 \mu \mathrm{l}$ of $5 \mathrm{X}$ Taq Master/ high yield (Jena Bioscience, GMBH, Germany) containing Thermostable DNA Taq polymerase buffer, dNTPs, (NH4) ${ }_{2} \mathrm{SO} 4, \mathrm{MgCl}_{2}$, and two pairs of primers 50 pmol. Double-distilled water was added to bring the final volume to $25 \mu \mathrm{l}$. The PCR assays were performed using a Thermal Cycler (Eppendorf). PCR assays were performed on bacterial DNA with Forward LF: 5'-CAA ACG TTA ACA ACG CAG TA-'3, Reverse LR: 5'-TCC AGA GTG ATC GAT GTT AA-'3 primers according to Bansal (Bansal, 1996). The predicted size based on the published nucleotide sequence of the listeriolysin (hly A) gene oligonucleotide primer combinations was $750 \mathrm{bp}$. The primers were ordered from Operon Company, (Operon, Japan) as nucleotide sequence. The amplification procedure consisted of an initial denaturation step at $95^{\circ} \mathrm{C}$ for $1 \mathrm{~min}$, followed by 35 cycles of denaturation at $94^{\circ} \mathrm{C}$ for $30 \mathrm{sec}$, annealing at $51{ }^{\circ} \mathrm{C}$ for $20 \mathrm{sec}$ and extension at $72{ }^{\circ} \mathrm{C}$ for $30 \mathrm{sec}$. A final extension step was carried out at $72{ }^{\circ} \mathrm{C}$ for 5 min. Aliquots from amplification reactions were analyzed by $1.5 \%$ agarose gel electrophoresis, viewed and photographed under UV light using gel documentation system (Biospectrum UVP, UK). Products of the appropriate sizes were identified by comparisons with a 100-bp DNA ladder (Gibco). In each PCR run, a non-template control was included to detect possible external DNA contamination.

\section{Experimental test for controlling $L$. monocytogenes in soft cheese:}

Manufacture of Damietta cheese according to (AbouDonia, 1986): Cheeses were manufactured in Dairy Technology Unit, Faculty of Agriculture, Suez Canal University, Ismailia, Egypt. Bacterial inoculum was prepared by serial dilution in Ringer's solution to reach a final level of $6 \log \mathrm{cfu} / \mathrm{mL}$.

Milk used in the experiment was divided into two parts one part treated with cold pressed Nigella Sativa (N. sativa) oil in $0.2 \%$ concentration and the other served as control without treatment. All milk parts were pasteurized at $80^{\circ} \mathrm{C}$ for $30 \mathrm{~min}$., cooled, adjusted to $45^{\circ} \mathrm{C}$, then calcium chloride and sodium chloride were added at levels of 0.02 and $5 \%$, respectively, and then inoculated with $2 \%$ of starter culture. Before renneting, N. sativa oil was added to one batch at concentrations of $0.2 \%$ and aliquot of 0.1 $\mathrm{mL}$ of the pathogen was inoculated into the two batches of pasteurized milk before manufacturing soft cheese, so that the final count of each becomes $5 \mathrm{log}$ cfu/g of cheese samples (Mahgoub et al., 2013).

Cheese samples were packed in sterile plastic containers within its whey and stored in the refrigerator at $5^{\circ} \mathrm{C} \pm 1$ for five weeks. Control and treated cheese samples were analyzed for L.monocytogenes, count during storage period at times $0,7,14,21,30$ and 35 days.

\section{Statistical analysis:}

Data were analyzed using independent t-test for the significance between two groups according to IBM SPSS software version 20. 


\section{RESULTS}

Table 1: Evaluation of Oxford agar and CHROMagar Listeria for isolation of L. monocytogenes

\begin{tabular}{lcccc}
\hline Type of sample & \multicolumn{2}{c}{ Oxford agar } & \multicolumn{2}{c}{ CHROMagar Listeria } \\
\cline { 2 - 5 } & No. & $\%$ & No. & 13.3 \\
\hline Buffalo milk & $1 / 15$ & 6.7 & $2 / 15$ & 6.7 \\
\hline Sheep milk & $1 / 15$ & 6.7 & $1 / 15$ & 26.7 \\
\hline Goat milk & $1 / 15$ & 6.7 & $4 / 15$ & 10 \\
\hline Kareish cheese & $2 / 30$ & 6.7 & $3 / 30$ & 13.3 \\
\hline Yoghurt & $0 / 15$ & 0 & $2 / 15$ & 13.3 \\
\hline Total & $5 / 90$ & 5.6 & $12 / 90$ & \\
\hline
\end{tabular}

\section{M $1,2 \quad 3 \quad 4$

\section{$750 \mathrm{bp}$}

(150

100

Fig. 1: The figure shows the UV picture after the agarose gel electrophoresis of PCR product. Lane M: the 100bp DNA ladder. Lanes from 1 to 3: L. monocytogenese positive samples (750 bp), Lane 4: control negative.

Table 2: Effect of N. Sativa oil on total Logarithmic count of L. monocytogenes in Damietta cheese

\begin{tabular}{lccc}
\hline Time / groups & Without treatment & With treatment & P-value \\
\hline Zero time & $5.30103 \pm 0.00$ & $5.30103 \pm 0.00$ & -- \\
\hline 1 week & $6.69897^{\mathrm{a}} \pm 0.18875$ & $5.47712^{\mathrm{b}} \pm 0.08731$ & $0.005^{* *}$ \\
\hline 2 week & $6.84509^{\mathrm{a}} \pm 0.132901$ & $5.69897^{\mathrm{b}} \pm 0.09281$ & $0.005^{* *}$ \\
\hline 3 week & $7.95424^{\mathrm{a}} \pm 0.02798$ & $4.90309^{\mathrm{b}} \pm 0.03152$ & $0.001^{* *}$ \\
\hline 4 week & $7.47712^{\mathrm{a}} \pm 0.20621$ & $4.77815^{\mathrm{b}} \pm 0.08732$ & $0.001^{* *}$ \\
\hline 5 week & $8.90309^{\mathrm{a}} \pm 0.03152$ & $3.84510^{\mathrm{b}} \pm 0.07394$ & $0.001^{* *}$ \\
\hline Total means & $7.19659^{\mathrm{a}} \pm 0.27169$ & $5.00057^{\mathrm{b}} \pm 0.14684$ & \\
\hline P-value & & $0.001^{* *}$ & \\
\hline
\end{tabular}

Log counts with different superscripts showed highly significant differences at $(\mathrm{P} \leq 0.01)$.

The original counts can be obtained by the antilogarithm (Base 10) of these results. 


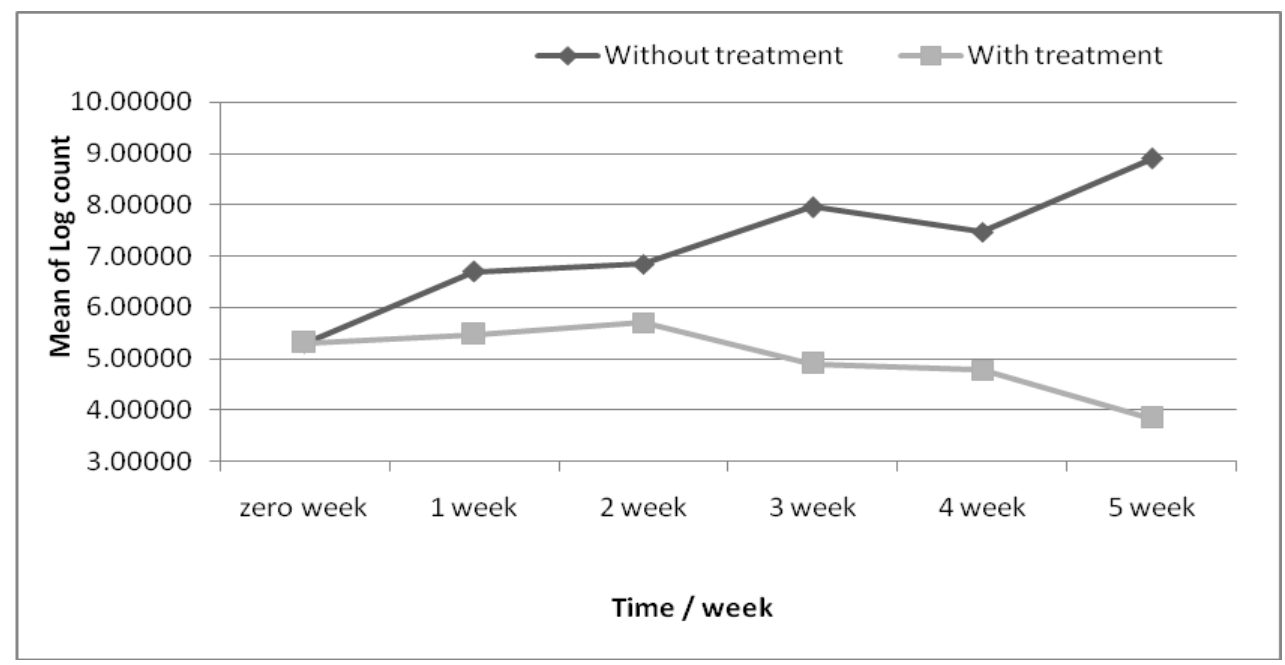

Fig. 2: Reduction in L. monocytogenes logarithmic count in cheese treated with N. Sativa oil compared with the non treated one

\section{DISCUSSION}

Milk and dairy products are highly perishable foods that may be incriminated in L. monocytogens infections. Listeriosis is the third leading cause of death among major pathogens transmitted commonly by food in USA (CDC, 2013). Foods most often associated with human listeriosis are ready to eat (RTE) products that support growth of $L$. monocytogenes through a long refrigerated shelf life and are consumed without further treatments (Jamali et al., 2013). There is a link between animals and their role as a source of infection for humans primarily from consumption of contaminated animal products (OIE, 2008).

Out of the 90 samples tested, 21/90 (23.3\%) were presumptively positive for listeria spp. on Oxford agar while $13 / 90 \quad(14.4 \%)$ were presumptively positive for listeria spp. on CHROMagar Listeria ${ }^{\mathrm{TM}}$. Further biochemical identification of the suspect colonies on Oxford agar and the chromogenic medium revealed that $5 / 21(23.8 \%)$ and $12 / 13$ $(92.3 \%)$ of the isolated organisms, respectively were confirmed as L. monocytogenes (Data not shown in tables).

By applying PCR technique, 3/90 (3.3\%) of the total examined samples and 3/12 (25\%) of biochemically confirmed isolates gave the specific band $(750 \mathrm{bp})$ (Fig. 1). These results agreed with Jami et al. (2010) and Mérdia et al. (2010) who recorded low prevalence rates of L. monocytogenes (4\% and 6.6\%) by PCR in raw milk and cheese, respectively.

Data in Table (1) revealed that the chromogenic medium performed better than Oxford agar medium in detection of L. monocytogenes. On CHROMagar
Listeria $^{\mathrm{TM}}$, L. monocytogenes produces blue colonies with white halos due to phospholipase activity. These colonies are distinctively different in phenotype from other Listeria species making selection of $\mathrm{L}$. monocytogenes much easier, and so improving the accuracy of confirmatory tests (Reissbrodt, 2004; Gouws and Liedemann, 2005 and Jamali et al., 2013). Some L. monocytogenes positive samples can go undetected on Oxford agar. Overgrowth by non pathogenic listeria spp. and/or phenotypically similar natural background flora can interfere with the isolation of this pathogen (Gouws and Liedemann, 2005). However, if one aims to detect Listeria spp., but not just L. monocytogenes, the combination use of traditional selective and chromogenic media are required to achieve higher recovery rate of Listeria spp.

The highest prevalence rate of $L$. monocytogenes was detected in goat milk (26.7\%) followed by buffalo milk \& yoghurt $(13.3 \%$ each) then kareish cheese $(10 \%)$ and finally sheep milk samples $(6.7 \%)$. Several authors could detect $L$. monocytogenes in the examined milk and dairy products. It was detected in $2.2-2.4 \% ; 1.8 \%$ and $2 \%$ in the examined goat milk samples as recorded by Gaya et al. (1996); AbouEleinin et al. (2000) and Nagah and Thabet (2003), respectively. El-Prince and Sayed (2004) recorded $L$. monocytogenes in $2 \%$ of examined milk and dairy products. Moreover, El-Malt and Abdel-Hameed (2009) reported the presence of L. monocytogenes in $6 \%$ of raw cow's milk.

Soft cheeses can be contaminated with Listeria spp. because they have a high water content and relatively neutral $\mathrm{pH}$, which facilitate bacterial growth. On the other hand, L. monocytogenes will not grow in cottage cheese but can survive. It has also been isolated on rare occasions from yoghurt as post 
processing contamination at $\mathrm{pH}>4.6$ (ADASC, 2000).

Cold-pressed black N. sativa oil contains a high level of hydrophilic phytochemicals including natural antioxidants. The consumption of this product may improve human health and may prevent certain diseases. Moreover, its antimicrobial activity is closely related to their phenolics content (Ahn et al., 2004). The broad spectrum antimicrobial activity of $N$. sativa oil could be attributed to the active constituents mainly Thymoquinon (TQ) and melanin (Bakathir and Abbas 2011 and Monika et al., 2013).

Results illustrated in Table (2) and Fig. (2) revealed a high significant reduction in the logarithmic count of L. monocytogenes $(\mathrm{P} \leq 0.01)$ in the sample treated with cold pressed N. sativa oil. These results agreed with Mahgoub et al. (2013) who recorded a reduction of L. monocytogenes count by adding N. sativa oil in Damietta cheese during storage period. The inhibitory effect of this oil against L. monocytogenes was also recorded by Chaieb et al. (2011) and Forouzanfar et al. (2014).

It's clearly evident that, L. monocytogenes could contaminate milk and ready to eat (RTE) dairy products which imposes a threat to health of consumers. This necessitates the application of strict hygienic measures on farm and during manufacturing of dairy products to prevent contamination of these products. The addition of N. sativa oil; a safe natural antimicrobial and immunostimulant additive, had a lethal effect on L. monocytogenes at refrigeration temperature, hence improving the keeping quality of cheese.

\section{REFERENCES}

Abou-Donia, S.A. (1986): Egyptian Domiati soft white pickled cheese. Journal of Dairy Science and Technology. 21, 167-195.

Abou-Eleinin, A.A.; Ryser, E.T. and Donnely, C.W. (2000): Incidence and seasonal variation of Listeria species in bulk tank goat's milk. Journal of Food Protection. 63(9): 1208-1213.

Ahn, J.; Grün, I.U. and Mustapha, A. (2004): Antimicrobial and antioxidant activities of natural extracts in vitro and in ground beef. Journal of Food Protection. 67(1): 148-155.

American Public Health association "APHA", (2004): Compendium of Methods for the Microbiological Examination of Food. $17^{\text {th }} \mathrm{ed}$, APHA, Washington D.C. USA.

Australian Dairy Authorities' Standards Committee (ADASC), (2000): Version 2.

Bakathir, H.A. and Abbas, N.A. (2011): Detection of the antibacterial effect of Nigella sativa ground seeds with water. African Journal of
Traditional Complementary and Alternative Medicines. 8(2):159-164.

Bansal, N.S. (1996): Development of a polymerase chain reaction assay for the detection of Listeria monocytogenes in foods. Letters in Applied Microbiology. 22(5): 353-356.

Centers for Disease Control and Prevention (CDC) (2013): Incidence and trends of infection with pathogens transmitted commonly through food - foodborne diseases active surveillance network, 10 U.S. sites, 1996-2012. MMWR, Morbidity and Mortality Weekly Report. 62(15): 283-287.

CDC (2015): Multistate Outbreak of Listeriosis linked to soft cheeses Distributed by Karoun Dairies, Inc. Centers for Disease Control and Prevention, 1600 Clifton Road Atlanta, GA 30329-4027 USA.

Center of Food safety and Applied Nutrition (CFSAN) (2001): Bacteriological Analytical Manual online, Listeria monocytogenes. U.S. Food \& Drug Administration, (Chapter 10), pp: 198-212.

Chaieb, K.; Kouidhi, B.; Jrah, H.; Mahdouani, K. and Bakhrouf, A. (2011): Antibacterial activity of Thymoquinone, an active principle of Nigella sativa and its potency to prevent bacterial biofilm formation. BMC Complementary and Alternative Medicine. 11:29.

Conly, J. and Johston, B. (2008): Listeria: A persistent food-borne pathogen. The Canadian Journal of Infectious Disease \& Medical microbiology. 19(5): 327-328.

El-Malt, L.M. and Abdel-Hameed, K.G. (2009): Occurrence of Listeria species in raw cow's milk and ice cream sold in Qena City. Assuit Veterinary Medicine Journal. 55(121):180190.

El-Prince, E. and Sayed, A. (2004): A survey on the presence of Listeria species in raw milk, ice cream and human stool with characterization of some isolates by SDS-PAGE. Assuit Veterinary Medicine Journal. 50(101): 94-109.

European Commission (2005): Commission Regulation (EC) No/2005 of 15 November 2005 on microbiological criteria for foodstuffs.

Forouzanfar, F.; Bazzaz, B.S. and Hosseinzadeh, H. (2014): Black cumin (Nigella sativa) and its constituent (thymoquinone): a review on antimicrobial effects. Iranian Journal of Basic Medical Sciences. 17(12): 929-938.

Gaya, P.; Saralegui, C.; Medina, M. and Nunez, M. (1996): Occurrence of Listeria monocytogenes and other Listeria spp. in raw caprine milk. Journal of Dairy Science. 79(11):1936-1941.

Gouws, P.A. and Liedemann, I. (2005): Evaluation of diagnostic PCR for the detection of Listeria monocytogenes in food products. Journal of Food Technology and Biotechnology. 43 (2): 201-205. 
Jamali, H.; Chai, L.C. and Thong, K.L. (2013): Detection and isolation of Listeria spp. and Listeria monocytogenes in ready-to-eat foods with various selective culture media. Food Control. 32: 19-24.

Jami, S.; Jamshidi, A. and Khanzadi, S. (2010): The presence of Listeria monocytogenes in raw milk samples in Mashhad, Iran. Iranian Journal of Veterinary Research. 11(4): 363-367.

Mahgoub, S.A.; Ramadan, M.F. and EL-Zahar, K.M. (2013): Cold pressed Nigella Sativa oil inhibits the growth of foodborne pathogens and improves the quality of Domiati cheese. Journal of Food Safety 33: 470-480.

Mérdia, R.L.G.; Salim, M.A.; Graterol, A.Y. and Gamboa, O. (2010): Detection of Listeria monocytogenes in white cheese by polymerase chain reaction (PCR). Archivos Latinoamericanos De Nutricion. 60 (3): 254260. (Abstract)

Monika, T.; Sasikala, P. and Vijaya Bhaskara Reddy, M. (2013): An investigational of antibacterial activities of Nigella sativa on mastaitis in dairy crossbred cows. International Journal of Advanced Technical Research. 3: 263-272.
Nagah, M.S. and Thabet, A.El-R. (2003): Incidence of Listeria species in goats and sheep milk and sheep milk cheese in Assuit Governorate. Assuit Veterinary Medicine Journal. 49 (98): 97-107.

Office International des Epizooties (OIE): OIE Terrestrial Manual 2008 Chapter 2.9.7. Listeria monocytogenes.

Reissbrodt, R. (2004): New chromogenic plating media for detection and enumeration of pathogenic Listeria spp. an overview. International Journal of Food Microbiology. 95(1): 1-9.

Roberts, D.; Hooper, W. and Greenwood, M. (1995): Practical food microbiology. London: Public Health Laboratory Service, pp: 146-149.

Silva, E.N.; Figueiredo, A.C.; Miranda, F.A. and Almeida, R.C. (2014): Control of Listeria monocytogenes growth in soft cheeses by bacteriophage P100. Brazilian Journal of Microbiology. 45(1): 11-16.

Sleator, R.D.; Gehan, C.G. and Hill, C. (2003): A postgenomic appraisal of osmotolerance in Listeria monocytogenes. Applied and Environmental Microbiology. 69(1): 1-9.

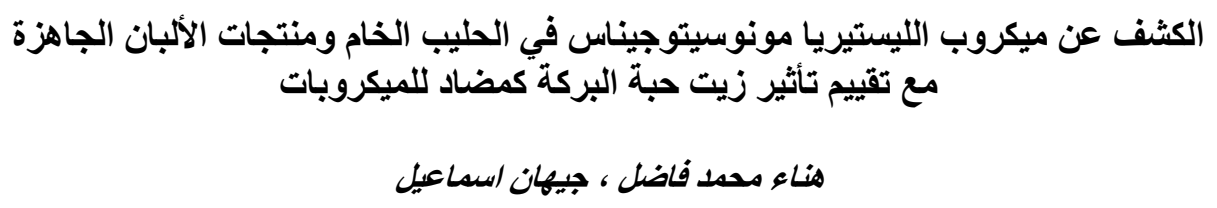

E-mail: Jehanismail14@yahoo.com Assiut University web-site: www.aun.edu.eg

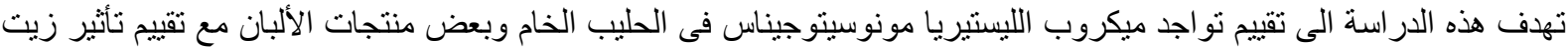

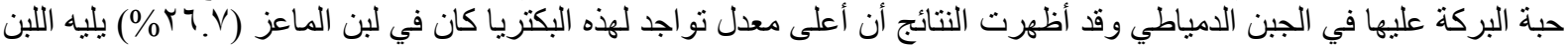

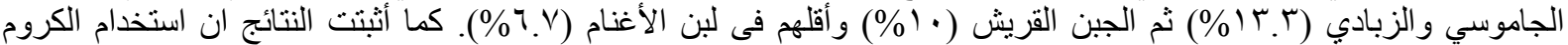

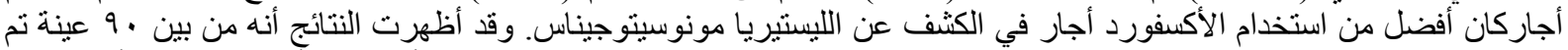

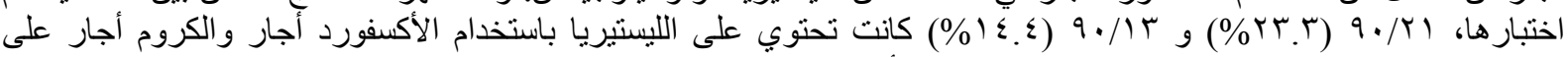

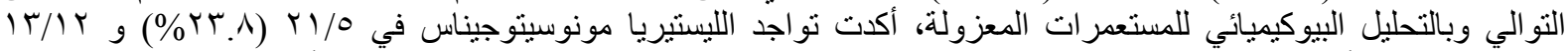

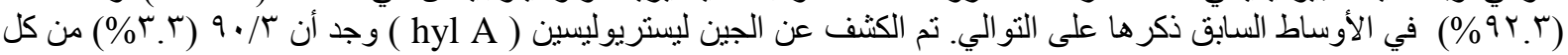

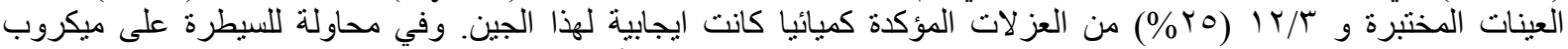

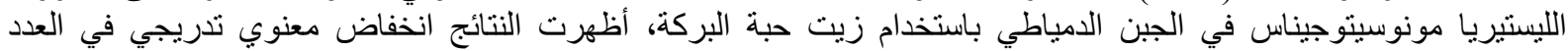

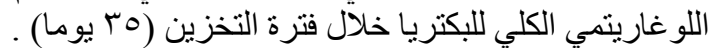

